\title{
Recent advances in the treatment of senile disciform macular degeneration by photocoagulation
}

\author{
A. C. BIRD \\ From the Retinal Unit, Moorfields Eye Hospital, City Rd, London \\ Contributed by request and dedicated to Sir Stewart Duke-Elder
}

In senile disciform macular degeneration the retina and pigment epithelium are elevated by serous fluid, which arises from subpigment epithelial fibrovascular tissue originating from the choroid. Disciform macular degeneration was described in the 19 th century (Oeller, 1893) and yet by 1939, when the "Text-Book of Ophthalmology" was being written, Duke-Elder (1940) could find only I 30 cases in the literature, and it appeared at that time to be an uncommon disease. During the last decade several factors have stimulated increasing interest in the disease. With increased longevity, disciform macular disease is becoming more prevalent and senile macular degeneration is now recognized as the most common cause of blindness in England and Wales (Sorsby, 1966). Since the advent of fluorescein fundus angiography, the morphology of the lesion may be studied during life (Gass, 1967) and in addition photocoagulation has provided a means of treating the disease.

Though drusen in the posterior fundus and senile disciform degeneration were described many years ago (Donders, I855; Oeller, I893, I905; Junius and Kuhnt, I926), it was not until I 940 that it was recognized that drusen and changes in the pigment epithelium were a predisposing cause of senile disciform macular degeneration (Gifford and Cushman, I940). It is now known that disciform macular degeneration is preceded by age-related changes in the posterior fundus. These changes are clinically recognizable as drusen and irregular pigmentation of the pigment epithelium. Drusen have been recorded in the third decade of life in families with dominantly inherited disease by Pearce (1968) and occasionally as early as 12 years of age by Deutman and Jansen (1970), though few patients develop drusen until late in life. Gass (1973) recorded an increase in the number and size of drusen with advancing age.

The pathogenesis of age-related epithelial change and drusen is uncertain. With increasing age, Bruch's membrane becomes thicker (Hogan 1967; Hogan, Alvarado, and Weddell, I97I). Collagen fibres are abnormally electron dense and irregular banded fibres appear in the inner collagen layer. Long dense osmiophilic fibres have also been seen and probably arise from collagen. The elastic zone becomes basophilic with increasing density of the fibres and deposition of needle-like crystals and calcium in the elastic fibres (Hogan and others, 197I). Accompanying the fibre changes there is deposition of PASpositive granular vesicular and filamentary material at first in the matrix of the inner collagen layer and later in the elastic layer. This material resembles amorphous vesicles 
in the pigment epithelial cells, and Hogan and others (I97 I) suggested that the abnormal material in Bruch's membrane arose from the pigment epithelial cells. It was also inferred that drusen were formed by accumulation of this amorphous material between the inner collagen layer of Bruch's membrane and the pigment epithelial basement membrane. A $\stackrel{\vec{F}}{\stackrel{*}{9}}$ recent study of the histochemistry and ultrastructure of drusen led Farkas, Sylvester, and Archer (197 Ia) and Farkas, Sylvester, Archer, and Altona (197 Ib) to suggest that drusen were formed after autophagic destruction of pigment epithelium cells by the abnormal action of pigment epithelial lysosomes.

The accumulation of amorphous material in Bruch's membrane seems to disrupt the ڤึ collagen fibres of the inner collagen layer. These fibres are inserted into basement membrane of the pigment epithelial cells and are responsible for the strong attachment of pigment $\vec{\omega}$ epithelium to the choroid (Hogan and others, I97 I).

Disturbance of the relationship between the pigment epithelial basement membrane and the choroid may allow spontaneous detachment of the pigment epithelium which is probably the initial morphological change in some disciform lesions (Gass, 1967 ; Teeters and Bird, I973a,b); this is the avascular stage of the disease. Such pigment epithelial detachments may resolve spontaneously, though a large majority are followed by invasion of the subpigment epithelial space by choroidal blood vessels to produce a vascular disci- $\rightarrow$ form lesion (Teeters and Bird, 1973b). It is likely that in other patients the initial morphological change is growth of choroidal blood vessels through Bruch's membrane and $\vec{\bullet}$ into the subpigment epithelial space without previous detachment of the pigment epi- $\nexists$ thelium. Once abnormal vessels are present in the subpigment epithelial space, the detachment is perpetuated by the constant transudation of plasma constituents from the abnormal capillaries into the subpigment epithelial space. The senile changes in the pigment epithelium and choroid allow widespread detachment of the pigment epithelium by this transudate. There is progressive growth of this abnormal fibrovascular tissue which may be accompanied by haemorrhage (Teeters and Bird, r973a, b), and permanent loss of vision results from prolonged detachment of the retina and damage to the subretinal tissues. Whilst loss of central vision is the rule in patients with disciform degeneration, a small minority maintain good visual acuity for several months (Teeters and Bird, i973b).

During the last 6 years the results of treatment of disciform degeneration by photocoagulation have been reported by many authors (Watzke and Snyder, r 968; Wise, Campbell, Wendler, and Rittler, I968; Zweng, Little, and Peabody, I968; Harris, I969; Jepson and Wetzig, I969; Little, Zweng, and Peabody, I970; Schneider, 1970; Cleasby, Fung, and Fiore, I97I; L'Esperance, I97I; Patz, Maumenee, and Ryan, I97ıa, b; Gass, I97 I, I973; Schatz and Patz, I973a, b; Bowbyes, Hamilton, Bird, Blach, Marshall, and Kohner, 1973). In the early reports (Zweng and others, 1968), the results of treatment in senile disciform degeneration were disappointing. With increasing experience better visual results have been obtained (Gass, I973; Schatz and Patz, I973a, b), although the value of photocoagulation in treatment of disciform degeneration has yet to be established.

In this paper the results of treatment of 83 disciform lesions in 81 patients with disciform macular degeneration is reported and the significance of these results assessed.

\section{Material}

During a 3-year period 81 patients with disciform macular degeneration have been treated by photocoagulation and have been followed up in the retinal unit. In two patients both eyes were treated, giving a total of 83 lesions; 79 were treated by argon laser photocoagulation, three by Xenon photocoagulation and one by both argon laser and Xenon photocoagulation. Eleven patients were 
below the age of 50 years, and all had dominantly inherited drusen or widespread pigment epithelial changes. The period of follow-up varied between 6 months and 3 years (average Io months).

These patients were referred to the Retinal Unit at Moorfields Eye Hospital from the general ophthalmic practices within the hospital. All avascular disciform lesions were treated when possible, and 59 vascular disciform lesions were treated and have had adequate follow-up. The patients in the second group were selected for treatment out of a much larger number of patients referred to the Unit with such lesions.

\section{Methods}

Disciform lesions were classified as avascular when there was detachment of the pigment epithelium, in which the subretinal and subpigment epithelial spaces were clear of exudate and blood, and in which no blood vessels were demonstrated by biomicroscopy or by fluorescein fundus angiography. 23 patients fell into this category; 22 had one eye treated and one both eyes. In ten patients there was s disciform lesion in the fellow eye. In avascular lesions, photocoagulation was applied in a continuous line around the periphery of the detachment and in a coarse grid over the central portion of the lesion avoiding the fovea. 22 patients were treated on one occasion only, and in two the treatment was repeated.

Lesions were classified as vascular when abnormal blood vessels were demonstrated by fluorescein fundus angiography, or there was blood or a large amount of exudate in the subretinal or subpigment epithelial spaces. Lesions in which the abnormal subpigment epithelial fibrovascular tissue was well shown and could be accurately localized were considered for treatment, and only those in which the tissue did not underly the fovea were treated. $5^{8}$ patients fell into this category; 57 had one eye only treated and one both eyes. In 36 cases the fellow eye had advanced disciform macular degeneration, and in 21 the posterior retina of the other eye was flat. Heavy confluent photocoagulation was applied to the whole of the vascular tissue. 45 lesions were treated on one occasion only, and fourteen on two or more occasions. One lesion was treated four times.

\section{Results}

\section{Avascular lesions}

Of the 24 pigment epithelial detachments treated, 2 I became flat after treatment, and have remained so during the follow-up period. In two cases the pigment epithelium remained detached after a single treatment. and for non-ophthalmic reasons were not re-treated. In the remaining patient, the pigment epithelium became flat after initial treatment with recovery of vision. After 6 months a fresh disciform lesion developed and vision fell to its original level of $6 / 36$.

The visual outcome in these patients is shown in Fig. I (overleaf). In fifteen patients, the visual acuity improved after treatment and pigment epithelial flattening, and in one the acuity fell by one line. In eight the acuity remained unchanged; five of these did not improve despite flattening of the retina though in only one was the acuity poor $(6 / 36)$, and this was ascribed to pigment epithelial changes. In the two patients with persistent detachment, the acuity was unchanged after 6 months $(6 / 24$ and $6 / 36)$. In twenty patients the acuity was $6 / 18$ or better at the end of the follow-up period.

\section{Vascular disciform lesions}

Of the 59 vascular disciform lesions treated, 43 became flat after one or more sessions of treatment. Of these two recurred during the follow-up period, and retinal flattening was achieved after re-treatment. One patient regained an acuity of $6 / 6$ after the second treatment. In the other, who had 6/1 2 after the initial treatment, the lesion recurred 6 months later and vision fell to counting fingers, but re-treatment caused the retina to flatten and 


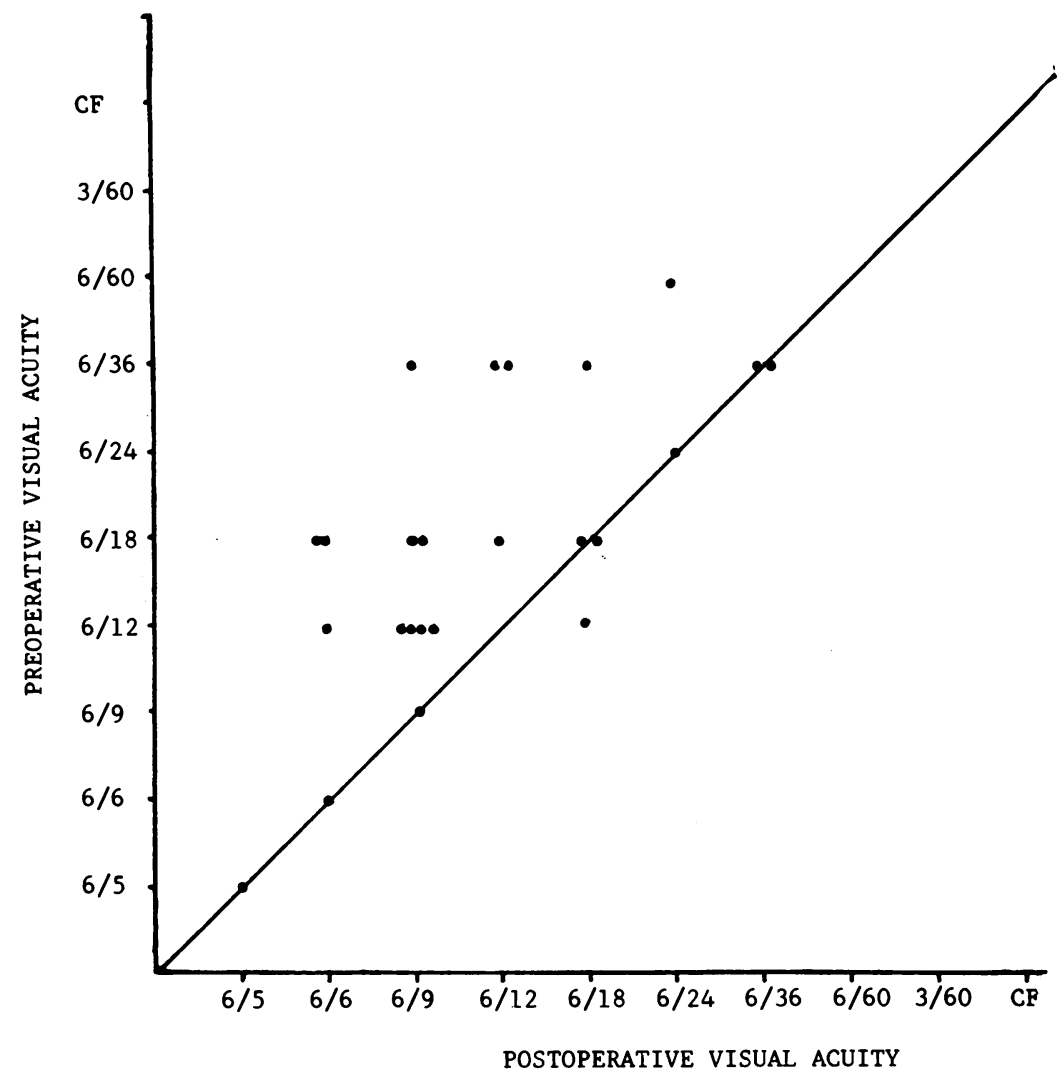

FIG. I Comparison between best corrected visual acuity before and after treatment in eyes with avascular pigment epithelial detachments. The diagonal is the no-change line. All foints above the line represent eyes in which the acuity improved, and all those below it eyes in which the acuity deteriorated

vision recovered to $6 / 36$. In fifteen patients the disciform lesion did not resolve. In one the lesion resolved, but recurred 6 months after the initial treatment, and was considered untreatable on the second occasion.

The visual outcome in these eyes is shown in Fig. 2 (opposite). Visual acuity improved in $3^{8}$ patients in whom retinal flattening was achieved, and in two the vision did not change. In three the acuity became worse: in one case, the acuity was lost following recurrence and retreatment, and in two it is likely that visual loss occurred as a result of neural damage due to photocoagulation.

A comparison was made between the clinical outcome and the distance from the foveola of the subretinal fibrovascular tissue, since this has a very important bearing on the feasibility of treatment (Table). It is evident that the prognosis, in terms both of retinal flattening and of visual recovery, varies directly with the distance of the edge of the fibrovascular tissue from the foveola. All lesions half a disc diameter (DD) or more from the fovea became flat, fifteen of sixteen of those one-quarter of a DD away flattened, and eleven of thirteen at one-eighth DD resolved. Lesions less than one-eighth DD from the fovea fared less well, since only fourteen of twenty flattened. This poor anatomical result in lesions proximal to the fovea is probably related to the reluctance to treat this region 


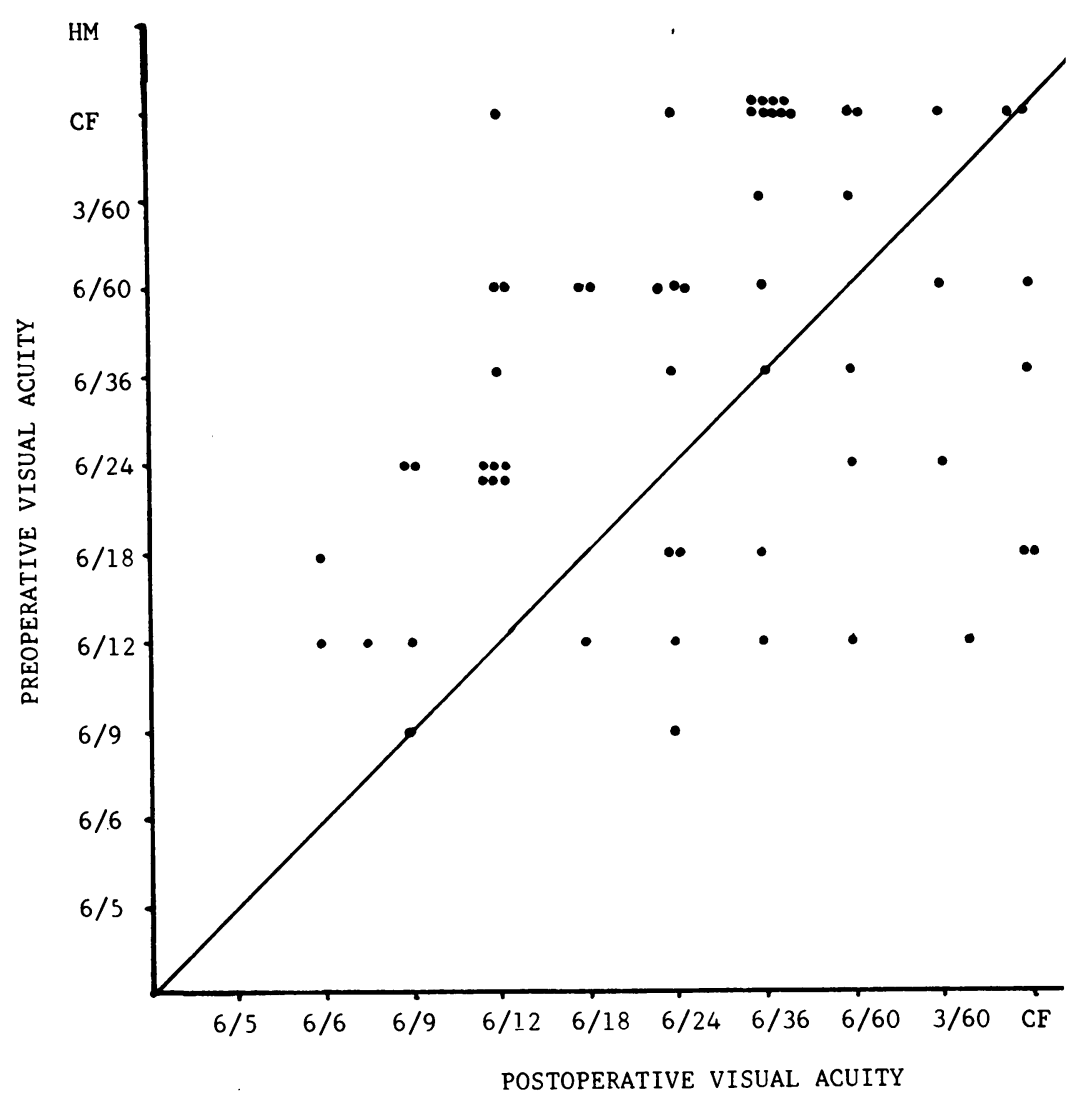

FIG. 2 Comparison between best corrected visual acuity befare and after treatment in eyes with vascular disciform lesions. The diagonal is the no-change line. All points above the line represent eyes in which the acuity improved and all those below it eyes in which the acuity deteriorated

Table Distance of subpigment epithelial vessels from foveola related to functional and anatomical results of treatment

\begin{tabular}{|c|c|c|c|c|c|c|c|c|c|c|}
\hline \multirow{3}{*}{$\begin{array}{l}\text { Final } \\
\text { visual } \\
\text { acuity }\end{array}$} & \multicolumn{5}{|c|}{ Retina flat after treatment } & \multicolumn{5}{|c|}{ Retina detached after treatment } \\
\hline & \multicolumn{5}{|c|}{ Proximity of Sub P-E vessels to fovea $(D D)$} & \multicolumn{5}{|c|}{ Proximity of Sub P-E vessels to fovea $(D D)$} \\
\hline & $\frac{1}{2}$ & $\frac{1}{4}$ & $\frac{1}{8}$ & o & Total & $\frac{1}{2}$ & $\frac{1}{4}$ & $\frac{1}{8}$ & o & Total \\
\hline & - & - & 一 & 一 & - & - & - & - & - & - \\
\hline $6 / 6$ & I & $\mathbf{I}$ & & & 2 & & & & & \\
\hline $6 / 7 \cdot 5$ & & & I & & I & & & & & \\
\hline $6 / 9$ & I & 2 & I & & 4 & & & & & \\
\hline $6 / 12$ & I & 6 & 3 & & 10 & & & & & \\
\hline $6 / 18$ & & 2 & I & & 3 & & & & & \\
\hline $6 / 24$ & & $\mathbf{I}$ & 2 & 3 & 6 & & I & & 2 & 3 \\
\hline $6 / 36$ & & 3 & 3 & 5 & I I & & & I & & I \\
\hline $6 / 6 o$ & & & & 4 & 4 & & & & 3 & 3 \\
\hline $3 / 60$ & & & & 2 & 2 & & & & 2 & 2 \\
\hline GF & & & & & & & & 2 & 5 & 7 \\
\hline & - & - & - & - & - & - & - & - & - & - \\
\hline Total & 3 & I5 & I I & 14 & 43 & 0 & I & 3 & 12 & 16 \\
\hline
\end{tabular}


heavily so that part of the lesion remained under-treated. The poorer visual results in flat lesions in which the fibrovascular tissue advanced to within less than one-eighth DD of the foveola must be related to damage of the subretinal and retinal tissues by the disease and by treatment. In these cases the retina often settled on fibrous tissue rather than on pigment epithelium. Of the three patients in whom the fibrovascular tissue was originally a quarter DD from the fovea and had a final vision of $6 / 36$ or worse, one had central pigment epithelial changes, one persistent retinal oedema, and one required treatment twice with growth of the vascular tissue in the interval between the two treatment sessions. Of the patients with a final visual acuity of $6 / 36$ or worse in the one-eighth DD group, two had finger counting vision originally, and one $3 / 36$, and all had permanent retinal changes.

\section{Discussion}

Pigment epithelial detachment in the presence of diffuse pigment epithelial changes and drusen, without invasion of the subpigment epithelial space by choroidal blood vessels, is followed in most patients by a vascular disciform lesion (Teeters and Bird, 1973b) with its attendant poor visual prognosis. Even in those patients in whom spontaneous flattening occurs, visual recovery may not take place, since retinal and pigment epithelial changes occur as a result of prolonged detachment (Teeters and Bird, r973b). Although the mechanism of flattening of these lesions after photocoagulation is unknown, the relatively high rates of therapeutic success and of visual recovery indicate that lesions of this type should be treated until flat. It is still uncertain that causing the retina to flatten will reduce the long-term risk of disciform lesions occurring, though there is little doubt that the short-term visual prognosis is improved. One patient out of 22 developed a disciform lesion 6 months after retinal flattening. Whilst there remains doubt with regard to the original assessment of the lesion in this case, there is no evidence of abnormal blood vessels in the subpigment epithelial space on fluorescein angiography when originally seen, or after flattening of the lesion. One recurrence in 22 is not more than would be expected from the natural course of the disease in patients with age-related changes in Bruch's membrane (Teeters and Bird, r973b).

Untreated vascular disciform lesions carry a universally poor visual prognosis, although in rare cases a reasonable degree of acuity is maintained for several months (Teeters and Bird, I973a, b). This stage of the disease represents the principal clinical challenge in the management of disciform macular degeneration, since a vast majority of patients present with vascular lesions. There is no doubt that certain disciform lesions may resolve after photocoagulation (Watzke and Snyder, 1968; Wise and others 1968; Zweng and others, I968; Harris, I969; Jepson and Wetzig, I969; Little and others, I970; Schneider, I970; Cleasby and others, I97 I L'Esperance, 1971 ; Patz and others I97 Ia, b; Gass, 197 I, I973; Schatz and Patz, 1973a, b; Bowbyes and others, 1973). Gass (1973), who regarded a visual acuity of worse than $6 / 60$ as unsatisfactory, pointed out that the visual result is often disappointing. With the help of low vision aids, however, patients who regain a vision of $6 / 36$ usually manage to read, though often with difficulty. Even those with visual acuity of better than $6 / 36$ may have severe difficulties, since the proximity of a dense scotoma near fixation is obtrusive, and many do not learn the art of eccentric fixation. In this series only sixteen patients out of $5^{8}$ had a visual acuity of worse than $6 / 36$ after an average followup period of 9 months, which is fewer than might have been expected from the natural course of the disease. 37 had an acuity of $6 / 36$ or better and sixteen of $6 / 12$ or better with 
flat lesions. It is hoped that these patients will preserve this level of visual acuity, since they no longer have a progressive lesion at the fovea. There is little doubt that they have benefited from treatment, at least in the short-term. The good response in these patients is related to selection of those in whom the fibrovascular tissue did not underly the fovea so that treatment could be applied to the whole area of vascular tissue without prejudicing foveal function. It appears that patients with vascular disciform lesions in which the fibrovascular tissue is one-eighth disc diameter from the foveola or more, have a reasonable prognosis after treatment, and that they should be treated without delay. This contrasts with the limit of one-quarter DD suggested by Gass (1973), which is perhaps too pessimistic. Although fourteen vascular lesions nearer than one-eighth DD flattened, only eight of the patients retained a visual acuity of $6 / 36$ or better, and the best was $6 / 24$. Whether these patients should be treated or not is open to doubt. This doubt will only be resolved by a controlled trial.

The techniques of treatment are important to the success or failure, as has already been pointed out (Schatz and Patz, I973a, b). The recent introduction of Argon laser photocoagulation with slit-lamp delivery allows a very accurate placement of treatment. This may account for the better results recorded in recent series, and in particular makes possible the successful treatment of lesions nearer the fovea than was possible with Xenon photocoagulation and with ophthalmoscopic delivery of Argon laser energy. In vascular lesions, treatment needs to be heavy and the photocoagulation lesions contiguous (Schatz and Patz, 1973). Frequently, the vascular tissue is not completely obliterated by the initial treatment session, and surviving peripheral capillaries may extend beyond the boundaries of the original lesion after treatment (Fig. 3). In some cases re-treatment is possible, and causes complete obliteration of the surviving vascular tissue with subsequent retinal flattening. Failure of the original treatment is frequently due to inadequate cover by photocoagulation though this is not always evident. It is now the practice at Moorfields Eye Hospital for patients to be reviewed with fluorescein angiography at 3-weekly intervals after treatment until all blood vessels are obliterated, or further treatment is thought to be unwarranted because of surviving vessels under the fovea. Unnecessary visual loss may result from foveal photocoagulation. Parafoveal coagulation may also prejudice the visual result since there appears to be energy absorption in the retina in this region with destruction of foveal receptor cells. It is likely that the light energy is absorbed by luteal pigment (Bowbyes and others, 1973), so that the energy of the coagulator should be reduced in the parafoveal region.

Whilst photocoagulation improves the visual prognosis in respect of the original lesion, it is unlikely that it reduces the risk of other disciform lesions arising in the same eye, since senile macular degeneration is a diffuse disease and disciform degeneration is multifocal. Three of the patients in this series had recurrences. The new lesion appeared on the edge of the flat scar, in one patient after I year and in the other 18 months after the original treatment; in the third patient the lesion appeared some distance from the original scar.

From the results in the patients reported here, it appears that treatment by photocoagulation is justified in lesions in which the fibrovascular tissue does not extend nearer than one-eighth DD from the foveola. Doubt still exists concerning those in which the blood vessels are nearer than one-eighth DD but do not underlie the foveola.

The patients treated in this series with vascular disciform lesions represent only i 5 per cent. of all such lesions referred to the retinal unit, though it is likely that earlier assessment would increase the percentage of treatable cases.

It should be emphasized that, while photocoagulation is the only effective method of 


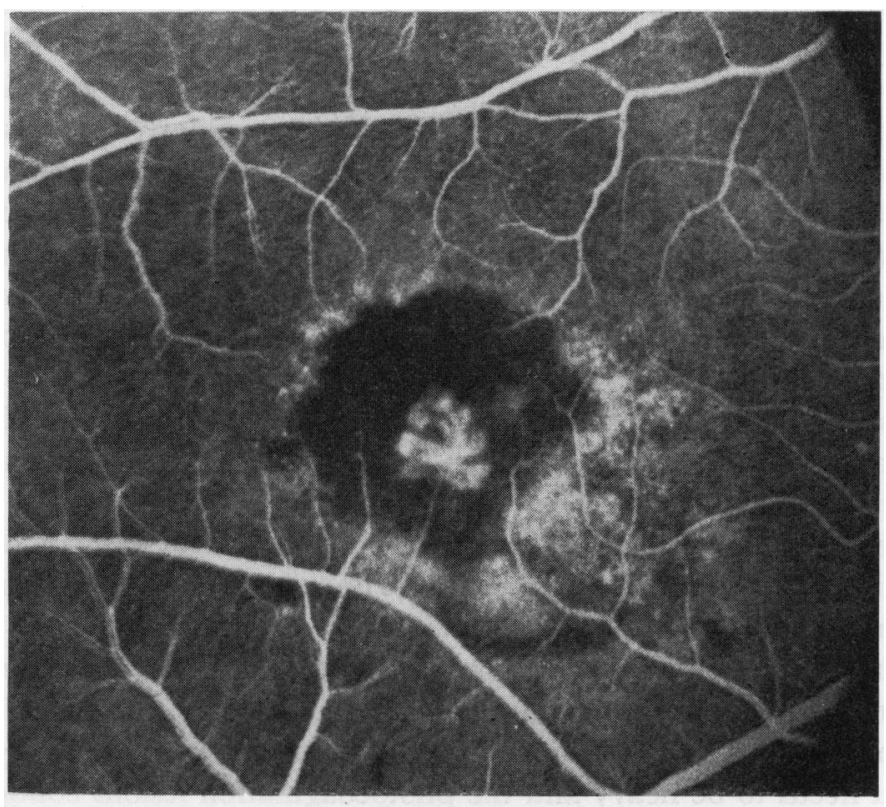

$3^{a}$

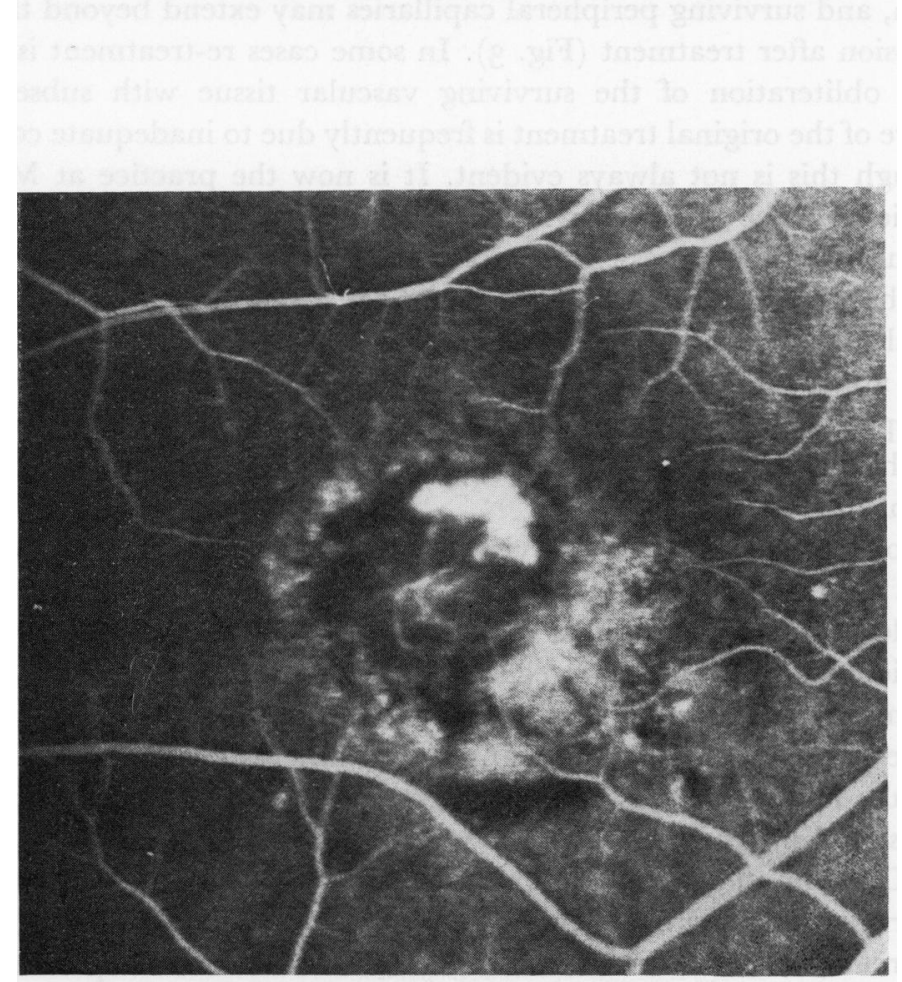

$3 b$ 


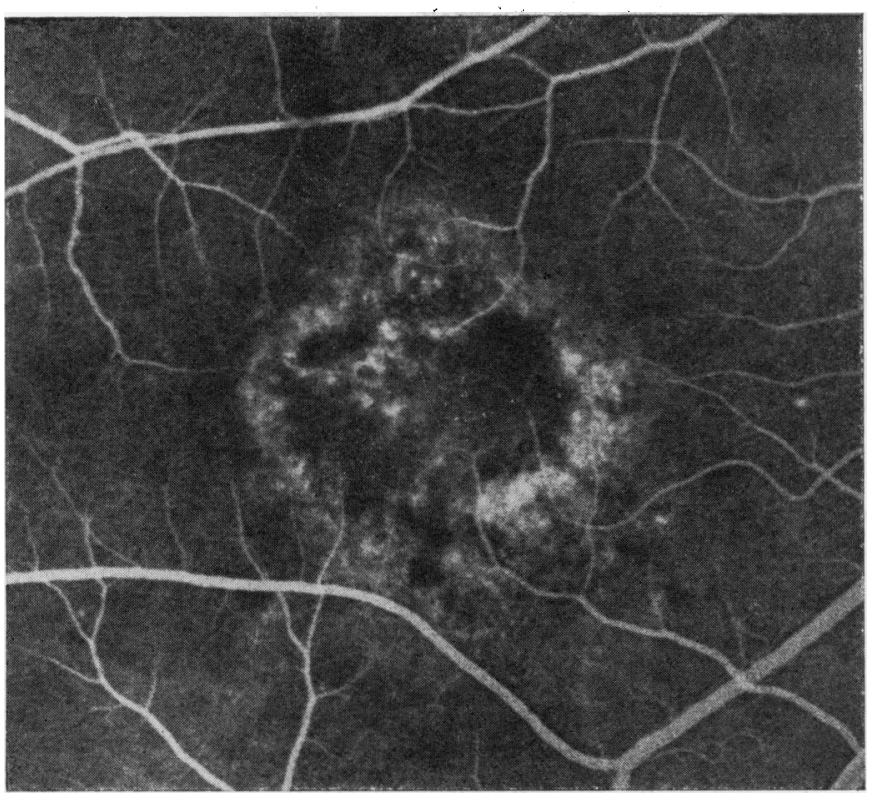

FIG. 3 A 59-year-old woman noticed visual loss $2 \frac{1}{2}$ months before referral. Fluorescein angiography demonstrated a treatable lesion (a) and argon photocoagulation was applied.

3 weeks later the retina was still detached and surviving capillaries were demonstrated on the nasal side of the lesion (b). Further photocoagulation was followed by flattening of the retina and closure of all vessels

(c)

treating disciform degeneration, it does not influence the basic disease process and that even after treatment the patient has a progressive fundus degeneration due to age.

Prophylactic photocoagulation treatment has been proposed in the past (Gass, 1970, 1971) though no reports have appeared in the literature giving results of its use. This treatment may be important in the future for prophylaxis to the second eye in patients with unilateral disciform lesions. About 12 per cent. of second eyes develop a disciform lesion each year (Teeters and Bird, 1973b, Gass, 1973), and no method has as yet been devised to distinguish those eyes at high risk from those at low risk. It is probably not justified to coagulate eyes on the basis of a risk of only 12 per cent. per year, and until a method is devised of identifying eyes at high risk, it is likely that prophylactic treatment will remain in abeyance.

\section{Summary}

83 senile disciform lesions, of which 24 were due to avascular pigment epithelial detachment and 59 were vascular disciform lesions, were treated by photocoagulation.

Retinal flattening was achieved in $2 \mathrm{I}$ of the first group, in two the detachment persisted after treatment, and in one a vascular disciform lesion occurred 6 months after retinal flattening. Visual acuity improved in fifteen patients.

In the second group, 43 vascular disciform lesions became flat after treatment, and this was accompanied by visual improvement in $3^{8}$ cases.

It is likely that photocoagulation is indicated in all patients with pigment epithelial detachments associated with diffuse age-related changes in Bruch's membrane and in the pigment epithelium. Treatment is also indicated in patients with vascular disciform lesions in which the subretinal vessels are no nearer than one-eighth disc diameter to the foveola.

I should like to thank the staff at Moorfields Eye Hospital for referring cases for treatment and in particular my colleagues in the retinal unit. I should like to thank also Mr. K. Shemi who has taken many of the fluorescein angiograms and Miss Rutter for secretarial assistance. 


\section{References}

BOWBYes, J. A., hamilton, A. M., BIRD, A. C., Blach, R. K., MARShall, J., and KOHNER, E. M. (1973)

Trans. ophthal. Soc. U.K., 93, 439

CLeAsBy, G. W., FUnG, W. E., and FIORE, J. v. (197I) Arch. Ophthal. (Chicago), 85, 18

Deutman, A. F., and Jansen, L. M. A. A. (1970) Brit. F. Ophthal., 54, 373

DONDERS, F. C. (1855) v. Graefes Arch. Ophthal., 1, abt. 2, p. 106

DUKE-ELDER, s. (1940) "Textbook of Ophthalmology", vol. 3, "Diseases of the Inner Eye", p. 2 I 16.

Kimpton, London

L'esperance, f. A. (1971) Trans. Amer. Acad. Ophthal. Otolaryng., 75, 609

farkas, T. G., SYlVeSter, v., and ARGher, D. (1971a) Amer. F. Ophthal., 7r, i 196

GAss, J. D. M. (1967)

-(197 I) Trans. Amer. Acad. Ophthal. Otolaryng., 75, 580

(1973) Arch. Ophthal. (Chicago), 90, 206

GIFFORD, S. R., and CUSHMAN, B. (1940) Ibid., 23, 60

haRRis, s. G. (1969) Canad. F. Ophthal., 4, 16

hOGAN, M. J. (1967) Trans. ophthal. Soc. U.K., 87, I 13.

- alvarado, J., and Weddell, J. E. (1971) "Histology of the Human Eye; An Atlas and

Textbook", p. 344. Saunders, Philadelphia

JePson, c. N., and WeTZig, P. c. (1969) Amer. F. Ophthal., 67, 920

JUNIUS, P., and KUHNT, H. (1926) "Die scheibenformige Entartung der Netzhautmitte: Degeneratio

maculae luteae disciformis". Karger, Berlin

little, H. L., zWeng, H. C., and peabody, R. R. (1970) Trans. Amer. Acad. Ophthal. Otolaryng., 74, 85 OELLER, J. (1893) “Atlas der ophthalmoskopischer Befunde". Bergmann, Wiesbaden

(1905) "Atlas Seltener ophthalmoskopischer Befunde". Bergmann, Wiesbaden

Patz, A., Maumenee, A. E., and Ryan, s. J. (I97ia) Trans. Amer. Acad. Ophthal. Otolaryng., 75, 569

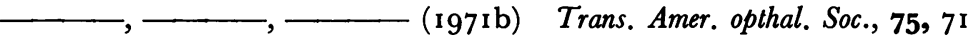

PEARCE, w. G. (1968) Brit. F. Ophthal., 52, 73

schatz, H., and PATZ, A. (1973a) Arch. Ophthal. (Chicago), 90, 183

- (1973b) Ibid., 90, 197

SCHNEIDER, R. J. (1970) Canad. F. Ophthal., 5, I 17

sorsBy, A. (1966) "The Incidence and Causes of Blindness in England and Wales, 1948-62",

p. 14. Reports on Public Health and Medical Subjects, No. I I4. H.M.S.O., London

TEETERs, v. W., and BIRD, A. c. (1973a) Amer. F. Ophthal., 75, 53 (1973b) Ibid., 76, I

Watzke, R. C., and SNYDER, W. B. (1968) Trans. Amer. Acad. Ophthal. Otolaryng., 72, 389

Wise, G. N., CAMpbell, C. J., Wendler, P. F., and rittler, M. c. (1968) Amer. F. Ophthal., 66, 452

zWeng, H. G., LITtLe, H. L., and PEABOdy, R. R. (1968) Trans. Amer. Acad. Ophthal. Otolaryng., 72, 377 